\title{
Power Injection on Single Phase Grid System
}

\author{
Fauzan Ismail $^{1)}$, Asnal Effendi ${ }^{2)}$, and Witrionanda ${ }^{3)}$ \\ ${ }^{1,2)}$ Department of Electrical Engineering, Institut Teknologi Padang, Indonesia \\ 3) Padang State Polytechnic, Indonesia \\ email: ${ }^{1)}$ fauzan.ismail@gmail.com , ${ }^{2}$ asnal.effendi@gmail.com, ${ }^{3)}$ witrionanda@yahoo.com
}

\begin{abstract}
Abstrak- This paper deals with power injection on single phase grid-connected inverter. The simple method is introduced to understand the concept of grid-connected systems. A Phase Lock Loop (PLL) method estimates the phaseangle of a grid system. The output of PLL is used to defines $I_{r e f}$, and the current of the inverter becomes feedback $\left(I_{\text {inv }}\right)$. Both current are derived to produce PWM using current mode controller method. As long as the grid system on fault condition like voltage distortion, therefore the single-phase inverter that connected into the grid should change the role and keep stabilization. The voltages sag and swell are the possible conditions that occurred on a power system. Voltage Sag is an event where the line voltage decreases from the nominal linevoltage for a short period of time. Voltage swell is the event when the line voltage increase from the nominal line voltage. By using PSIM software, the injection and absorption of power into a grid system is verified during a voltage sag, swell, and normal. The simulation shows the change of $I_{d c}$ toward grid voltage and current, voltage and current of the inverter, also active and reactive power flow is injected into the grid, or inverter becomes a load, and inverter absorbs reactive power. The waveform of the measured parameter is analyzed to define the role of inverter toward the grid. The result shows the performance of the proposed inverter to absorb reactive power during the swell, and inject reactive power when sagging.
\end{abstract}

Keywords: Power injection, grid-connected, photovoltaics, renewable energy, voltage sag and swell.

\section{INTRODUCTION}

Renewable energy sources are an alternative source to support the electric power system. Solar photovoltaics (PV) is a dominant source to be applied to the interconnected power system [1] or applied separately with a stand-alone system. There are many methods is integrated on the inverter to be ably connected perfectly into the grid system.

In [2] reviewed the trend of PV power plants development that analyze grid codes for fault ride through (FRT), voltage, frequency, active power, and reactive power. As reviewed by [3] the harmonics problems are caused by poor quality supply on grid-connected inverter can reduce the performance of the system. The IEEE 519 standards allow a limit of 3\% THD (Total Harmonics Distortion) for special application and 5\% THD for general application [4]. Harmonics are caused by switching component that carries the distorted signal, but when the switching component with the best method is integrated on the inverter will reduce harmonics. An increasing switching frequency in the PWM method can reduce current total harmonic distortion, but increases the switching loss. The variable switching frequency technique in [5] proposed to reduce switching loss also requires an accurate model of ripple current with complicated calculation and low dynamic response. The multilevel inverter in [6] is also used to reduce the current harmonic content. But they have complicated control and many powers switches increase the cost. The hysteresis technique in [7] also reduce switching loss and current THD, but it is also not robust. So many others control strategy and optimization can implement in this case.

The grid-connected system between a secondary source and primary source describes two conditions when the secondary absorbs or injects the power. The experiment conducted by [8] describes the three areas of reactive power control with sliding mode control; (1). Reactive power absorbed by PV inverter, (2) inject the maximum active power into the grid, then (3) reactive power is injected into the grid. Synchronous Reference Frame method is also implemented in [9], that active power injection and reactive power compensation for harmonics current suppression was verified and generate low current THD.

The concept of power-sharing between the grid and local source will support the loads and utility grid. The distributed generation is involved to inject the active and reactive power to the local loads and support the utility grid through the injection of extra power from the dispersed energy source to the main grid has been discussed by [10].

This paper will simulate and verify the power injection during the normal mode and voltage distortion by implements a Phase Locked Loop (PLL) and a current mode controller.

\section{Single Phase Grid Synchronization}

The technical issue remains to be considered for integration of renewable energy resource into a grid system. Because the renewable energy source should inject the active power and also be able to absorb the reactive power due to this interconnection. Where the output voltage waveform of the inverter has to be synchronized with the grid voltage to secure from unstable operation [11]. The block diagram of a single phase grid-connected photovoltaics system displayed in Figure.1. The PLL method with a lowpass filter for system synchronization will generate a phase angle (theta). Refer to current inverter and phase angle, therefore, the PWM signal is generated. 


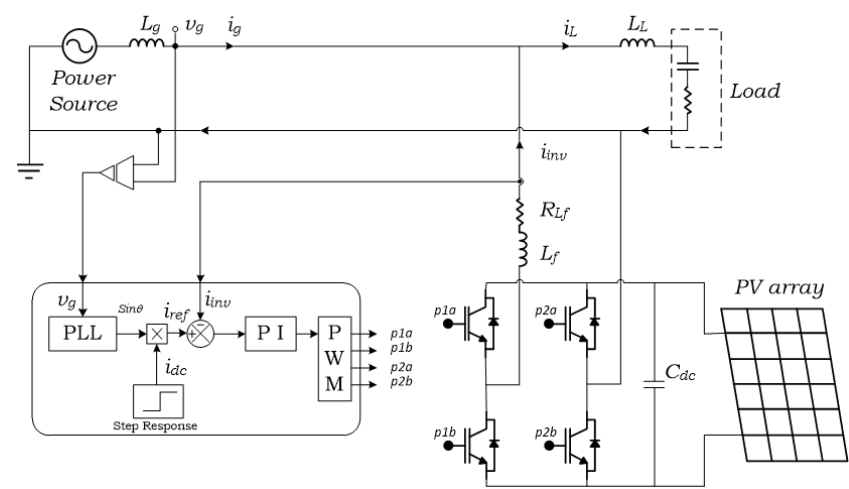

Figure 1. Single Phase Grid Connected Photovoltaics System

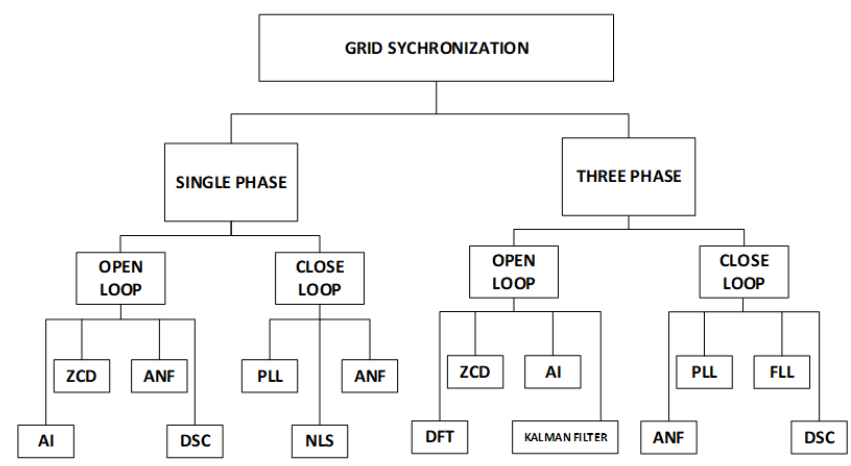

Figure 2. Single Phase Grid Connected

\section{A. The Control Structure of a Single Phase Grid Connected System}

Figure 2. shows the grid synchronization method discussed in [12]. Classification of PLL method for grid synchronizing is analyzed to find a better method of PLL. The PLL is the essential component of the grid-connected inverter for synchronizing parameter of voltage, frequency, and the phase angle between inverter output and grid system [13].

Since the input signal PLL is sinusoidal that denoted as A. $\operatorname{Sin}\left(\theta_{i}\right)$, therefore the $\mathrm{V}_{\mathrm{err}}$,

$$
V_{e r r}=A \operatorname{Sin}\left(\theta_{i}\right) \cdot \operatorname{Cos}\left(\theta_{e}\right)-\operatorname{Sin}\left(\theta_{e}\right) \cdot \operatorname{Cos}\left(\theta_{e}\right)
$$

The PLL consists of Phase error Detection (PD), Loop Filter, and Voltage Control Oscillator (VCO). Where the reference input of PLL is measured from the output of inverter voltage to estimate the utility grid phase angle $(\theta)$. Figure 3 . Shows a block diagram of PLL for single-phase grid-connected inverter.

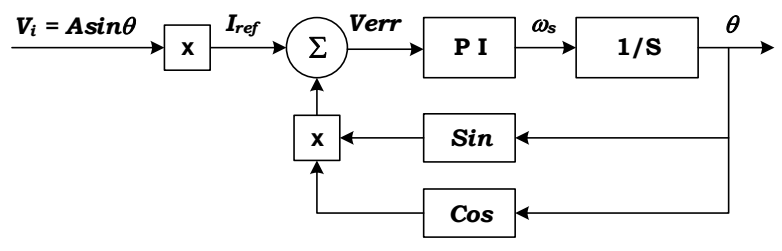

Figure 3. PLL Block Diagram

The estimates $\theta$ that is calculated by PLL becomes an essential parameter to calculate $\mathrm{I}_{\text {ref, }}$

$$
I_{\text {ref }}=I_{d c} \cdot \sin \theta
$$

Then, the error current between $\mathrm{I}_{\text {ref }}$ and $\mathrm{I}_{\text {inv }}$ is used to generate PWM via PI controller, which is called current mode controller. The $\mathrm{I}_{\mathrm{inv}}$ is calculated by the following equation;

$$
\begin{aligned}
& I_{L}=I_{i n v}+I_{g} \\
& I_{i n v}=I_{L}-I_{g}
\end{aligned}
$$

Hence, the block diagram of current mode control can be described in Figure.4.

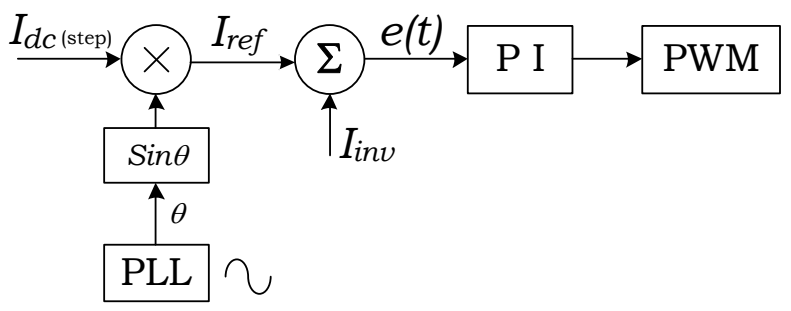

Figure 4. Single Phase Grid Connected

B. Power Analysis on Single Phase Grid Connected Inverter

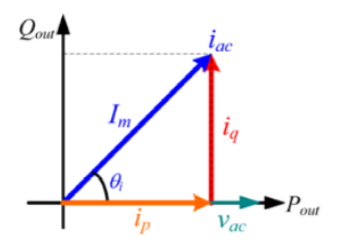

Figure 5. The phasor diagram of the ac output current

The power system identifies both active and reactive current is produced by resistive, inductive, and capacitive component. Phasor diagram of the ac source was displayed in Figure 5, where the grid voltage is assumed purely sinusoidal waveform. Active power is produced by the current component $i_{p}$, which is in phase with grid voltage $v_{a c}$ [14]. Reactive power is controlled by the current $i_{q}$ which is $90^{\circ}$ out of phase with the voltage $v_{a c}$. Hence, the amplitude $i_{p}$ and $i_{q}$ is expressed as, $I_{p}=I_{m} \cos \theta_{i}$

$$
I_{q}=I_{m} \sin \theta_{i}
$$

where $I_{m}$ and $\theta_{i}$ are the amplitude and phase angle of current $i_{a c}$. The voltage and current waveform can be expressed,

$$
\begin{aligned}
& v_{a c}(t)=V_{m} \sin \omega t \\
& i_{a c}(t)=I_{m} \sin \left(\omega t-\theta_{i}\right)
\end{aligned}
$$

Figure 6. shows grid voltage and current waveform to calculate Active and Reactive Power. When the $v_{a c}$ is a maximum or at $90^{\circ}$, the amplitude of ac current is expressed: 
$i_{a c}\left(t_{p}\right)=I_{m} \sin \left(\frac{\pi}{2}-\theta_{i}\right)=I_{m} \cos \theta_{i}$

by detecting zero crossing point of the grid voltage $v_{a c}$ and calculates total sampling for one period, then current $i_{p}$ can be measured by delaying quarter of ac line period. Equation (9) reveals that a number of the sample at the time $t_{p}$ is equal to the amplitude of active current component $i_{p}$. Thus, an active power inverter can be determined as:

$P_{\text {out }}=\frac{1}{2} V_{m} I_{m} \cos \theta_{i}=\frac{1}{2} V_{m} I_{a c}\left(t_{p}\right)$

the amplitude of ac current at the time $t_{q}$,

$i_{a c}\left(t_{q}\right)=I_{m} \sin \left(\pi-\theta_{i}\right)=I_{m} \sin \theta_{i}$

then, the reactive output power of the inverter becomes:

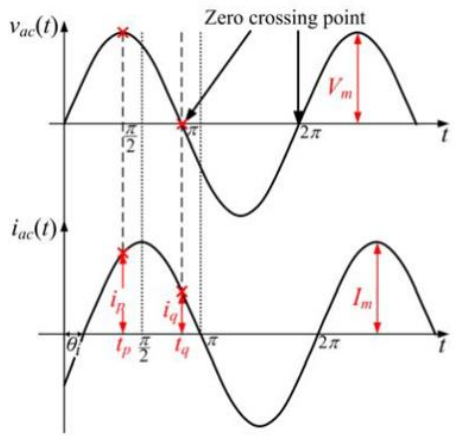

Figure 6. voltage and current waveform of ac source

\section{Sag and Swell Condition During Grid Connected}

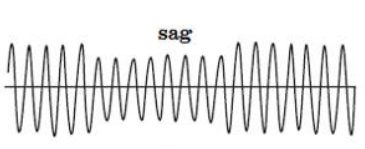

a

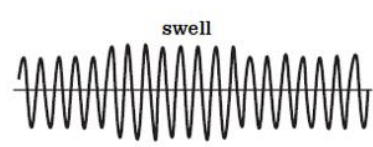

b
Figure 7. voltage distortion: (a) voltage sag, (b) voltage swell

A voltage sag and swell are displayed in Figure 7 explained by [11]. Voltage Sag is an event where the line rms voltage decreases from the nominal line-voltage for a short period of time. Less than $80 \%$ for more than one period of sagging condition occurred. It is caused by a large load on the line experiences a line-to-ground fault. Then voltage swell is the converse of the sag. It is event the line rms voltage increase from the nominal line-voltage, and the reactive power also increases during swell condition [8]. To reduce the voltage rise on the grid system, therefore, the inverter connected to the grid should play a role to absorb reactive power from the grid. During voltage sag, reactive power is injected into the grid to support grid voltage. Whereas in normal voltage, injection maximum active power into grid occurred.

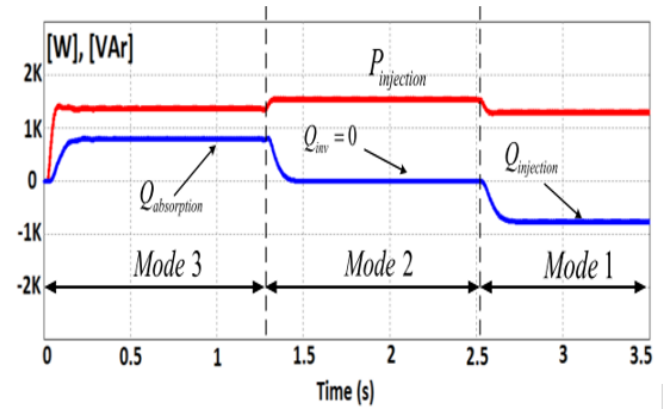

Figure 8. The output current of the AC module with the different grid voltage

Figure 8 explained three mode operation of a single phase grid-connected inverter. Mode 1 shows the reactive power injection from the inverter to improve the voltage profile during the sagging condition. Mode 2 explained that inverter injects an active power into the grid system and the voltage profile on normal condition. Mode 3 shows reactive power absorption. It occurs on voltage swell and the inverter can play the role as the inductive and capacitive load.

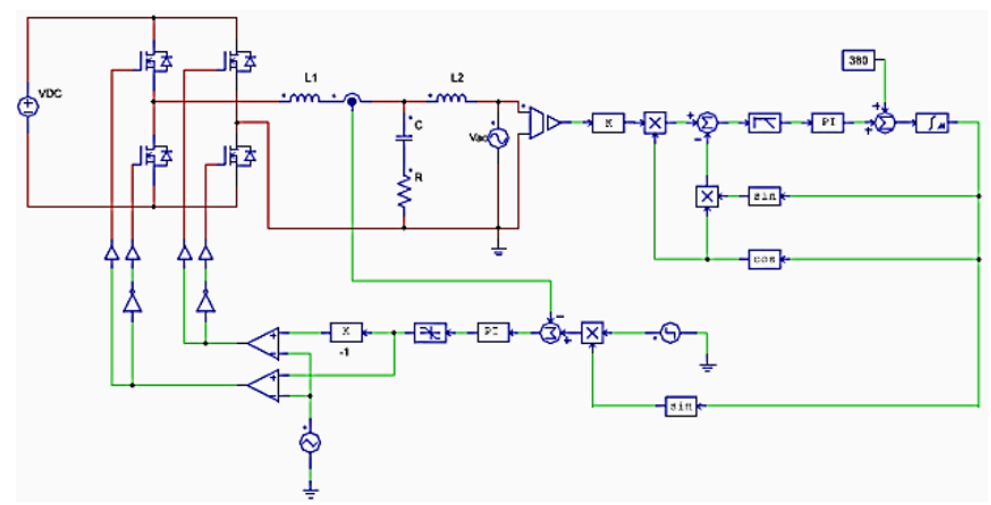

Figure 9. PSIM Simulation of Single Phase Grid Connected Inverter

\section{Proposed Design of Single Phase Grid Connected Inverter}

The proposed inverter applies a conventional PLL circuit with a low pass filter to generate the phase angle. The current control mode is implemented to generate four PWM signal to drives inverter. Figure 9. is configured to simulate power injection from a single- phase inverter into the grid system with the parameter in Table 1.

Table 1. The parameter of the single-phase inverter

\begin{tabular}{cc}
\hline $\begin{array}{c}\text { Parameter/ } \\
\text { Component }\end{array}$ & Value / Type \\
\hline$V_{d c}$ & $400 \mathrm{~V}$ \\
\hline$V_{g}$ & $220 \mathrm{~V}$ \\
\hline$R$ & $50 \mathrm{ohm}$ \\
\hline$C$ & $2.5 \mathrm{uF}$ \\
\hline$L_{l}$ & $200 \mathrm{uH}$ \\
\hline$L_{2}$ & $340 \mathrm{uH}$ \\
\hline$f_{\mathrm{c}}$ & $10 \mathrm{kHz}$ \\
\hline MOSFET & IRFP460 \\
\hline
\end{tabular}




\section{RESUltS AND DISCUSSION}

The inverter topology is displayed in Figure 1 and simulated using PSIM software. Simple PLL algorithm and current control mode are applied to prove the concept of a grid-connected system on single phase circuit. This simulation observes changes of $\mathrm{V}_{\mathrm{dc} \_ \text {step }}$ value that trigger by step signal, and also discuss grid-connected inverter on normal voltage $\left(v_{p}=311\right.$ volt) and distorted voltage. The voltage sag and voltage swell are demonstrated during power injection. Unstable frequency is also simulated to discuss the performance of the system. Finally, the actions of an inverter that relates to power during fault condition occur on a gridconnected system are explained.

The proposed grid-connected inverter is designed by using current mode control and PI controllers with setting consist of gain $=0.5$ and time constant $=5$. Firstly, the measured $\mathrm{v}_{\mathrm{g}}$ will be used by the PLL algorithm to calculate theta $(\theta)$. The $\mathrm{V}_{\mathrm{dc} \_ \text {step }}$ represents $\mathrm{I}_{\mathrm{dc}}$ and $\sin \theta$ are multiplied and produce $\mathrm{I}_{\text {ref. }}$. The $\mathrm{I}_{\text {inv }}$ and $\mathrm{I}_{\text {ref }}$ will be summed to produce error before calculated by the PI algorithm, then PI generates PWM to drives the IGBT.

Figure 10-13. describes power injection and absorption on grid-connected inverter during normal grid voltage. Figure 10. Shows the first experiment, a grid system is loaded by the inverter circuit. When the Idc is equal to 0 volts. Practically, the measured $v_{g}$ and $v_{\text {inv }}$ should the same phase angle before connected. As long the inverter is connected into the grid, the currents of inverter become a parameter to be noticed. When the phase difference between vg and vinv is 180 degree, so the current flow inside to inverter and the inverter becomes a load.

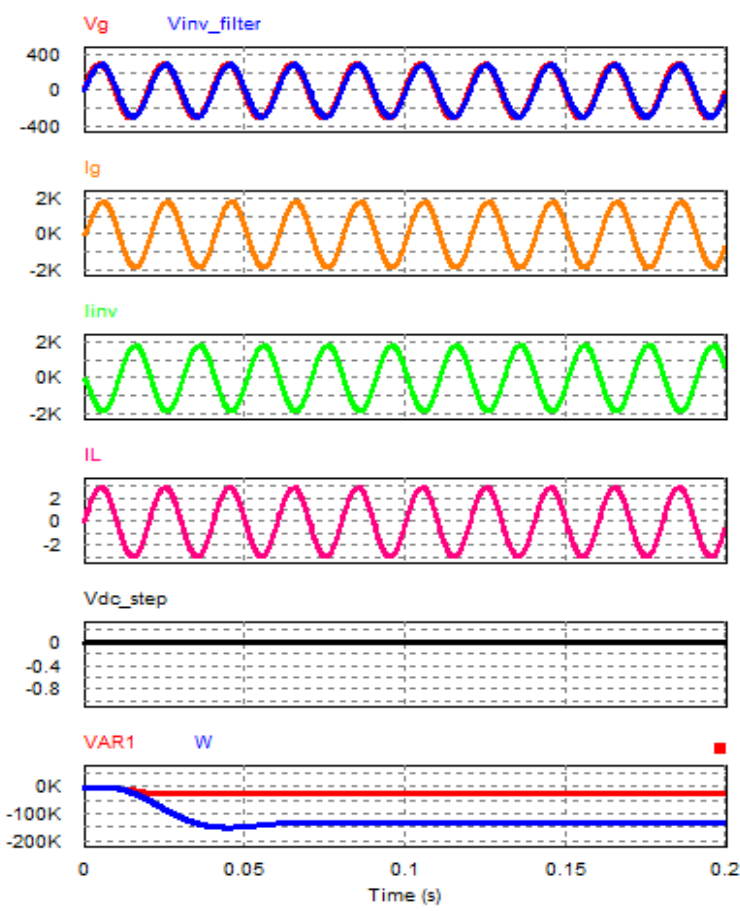

Figure 10. Inverter become a load during connected into the grid

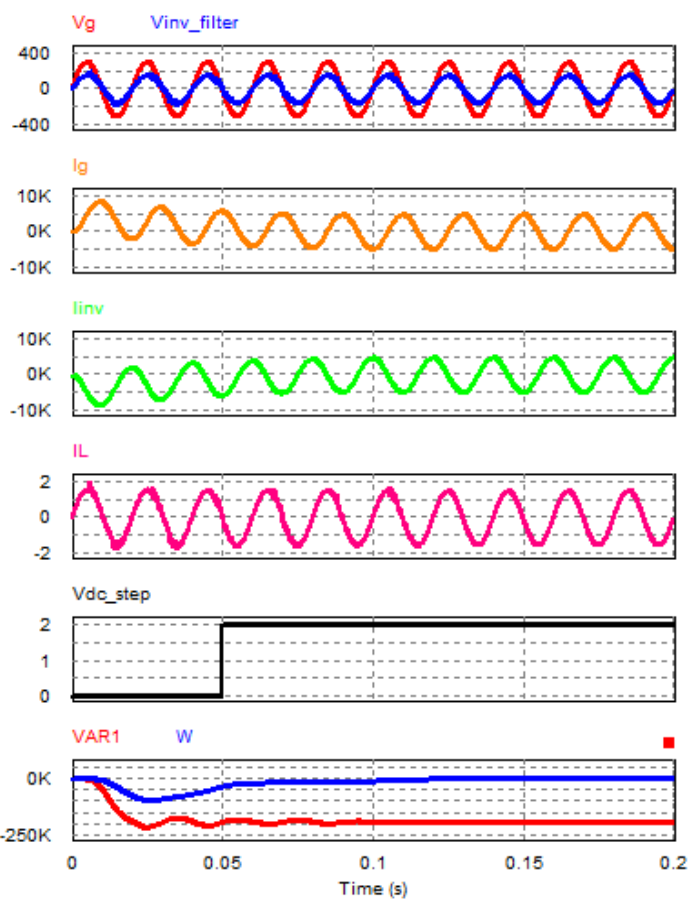

Figure 11. Reactive Power Injection.

The lagging reactive power injection with no active power injection is explained in Figure 11. The $\mathrm{V}_{\mathrm{dc} \_ \text {step }}$ setting with time step $=0.05 \mathrm{~s}$ and $\mathrm{v}_{\text {step }}=2$. Before time step 0.05 so the $\mathrm{V}_{\text {step }}=0$, and $\mathrm{I}_{\mathrm{g}}$ lagging toward $\mathrm{V}_{\mathrm{g}}$. It means the inverter becomes load and inverter also produce reactive power. The harmonics appear on disturbed $\mathrm{I}_{\mathrm{L}}$. After time step 0.05, the $0^{\circ}$ of grid voltage is equal to $90^{\circ}$ of inverters current. This means there is no active power injected into the grid, and only the reactive power is injected.

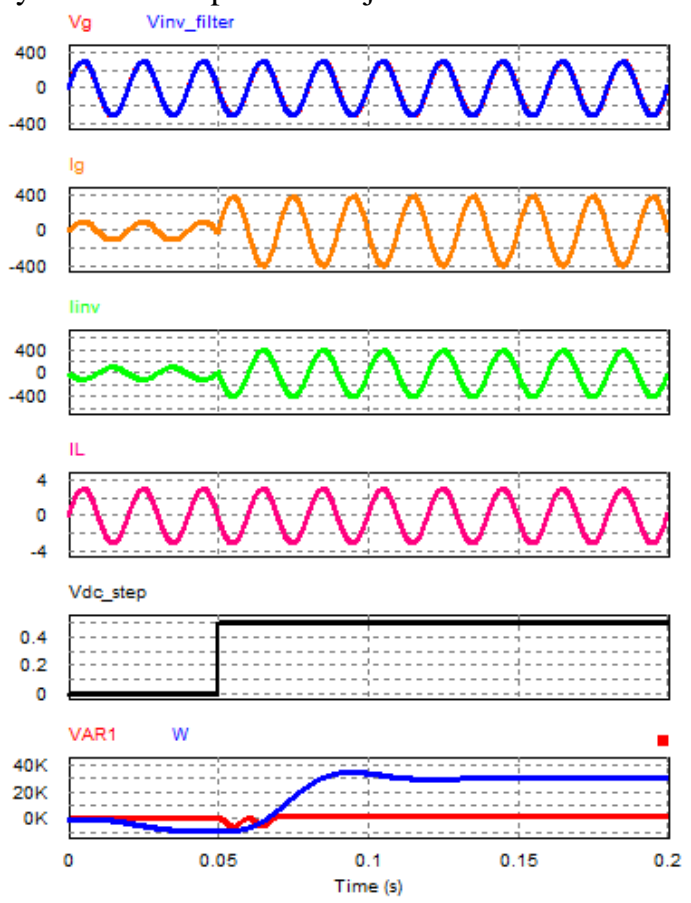

Figure 12. Active Power Injection. 
The active power injection displays current of inverter and grid voltage with the same phase, or both waves with zero phase angle are shown in Figure 12. When $\mathrm{v}_{\text {step }}=0$ or time-step is less than 0.05 , therefore $V_{g}, V_{\text {inv }}, I_{g}$ and $I_{L}$ have zero phase difference and 180-degree phase difference towards the $\mathrm{I}_{\text {inv. }}$ The wave states that the inverter becomes a load. After time-step is greater than 0.05 and $\mathrm{v}_{\text {step }}=0.5, \mathrm{I}_{\mathrm{L}}$ and $\mathrm{I}_{\text {inv }}$ are in phase with $\mathrm{V}_{\mathrm{g}}$ and $\mathrm{V}_{\text {inv }}$. That means the inverter injects active power into the grid system.

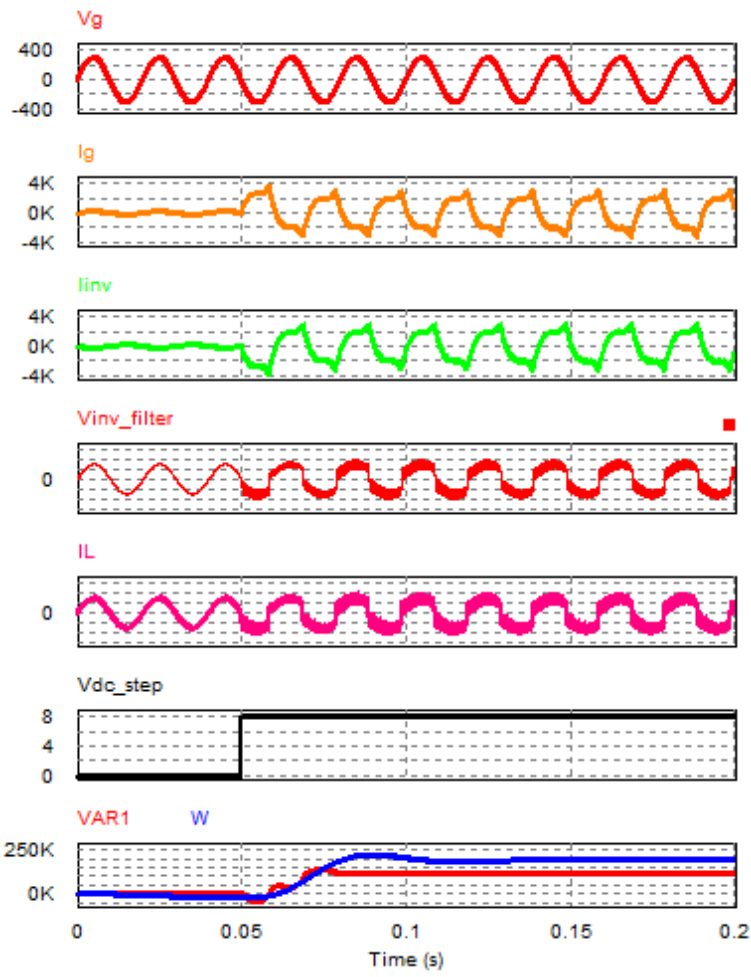

Figure 13. Reactive Power Absorption by Inverter

The Inverter system can also absorb the reactive power from the grid, which is described in Figure 13. When vstep $=0$ or time-step is less than $0.05 \mathrm{~s}$, the active and reactive power tend to negative, then after $0.05 \mathrm{~s}$ and vstep $=8$ both power also tends to positive. The $\mathrm{Vg}$, Vinv, Ig and IL in zero phase difference, and Iinv lagging 180-degree. It means the currents flow to an inverter with a reactive component.

This simulation also employe the inverter during voltage sag and voltage swell. Figure 14 and 15 shows inverter action on voltage distortion like sag and swell. During sag testing, the grid voltage is set to 200 volts and the vstep $=0$ for time-step is less than 0.05. Then Vgand Vinv are not in phase with the harmonics seen on Vinv. after time-step greater than $0.05 \mathrm{~s}$ and vstep $=0.2$, the $\mathrm{Vg}$ and Vinv in zero phase difference and the eliminate harmonics for Vinv. Whereas, for a swell simulation, the voltage is $380 \mathrm{~V}$. Ig and Iinv have harmonic components during time-step less than 0.05 and vstep $=0$. the harmonics component can be reduced after time step more than $0.05 \mathrm{~s}$. the inverter injects the active current during swell condition by triggering Vstep $=1$.

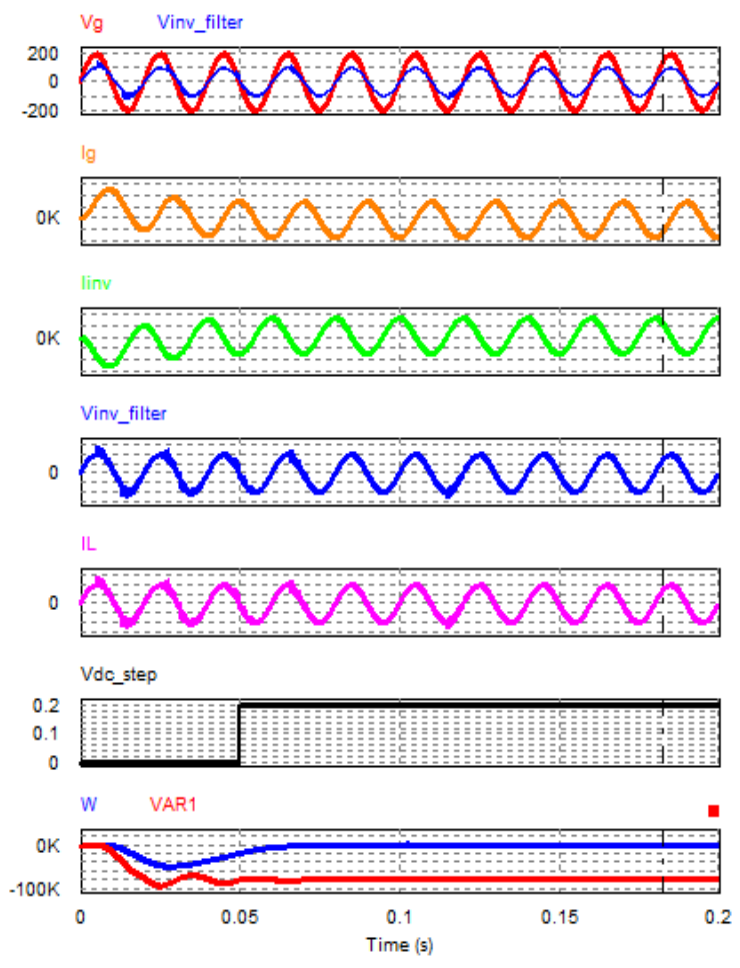

Figure 14. Grid-connected during voltage sag $(\mathrm{Vg}=200)$
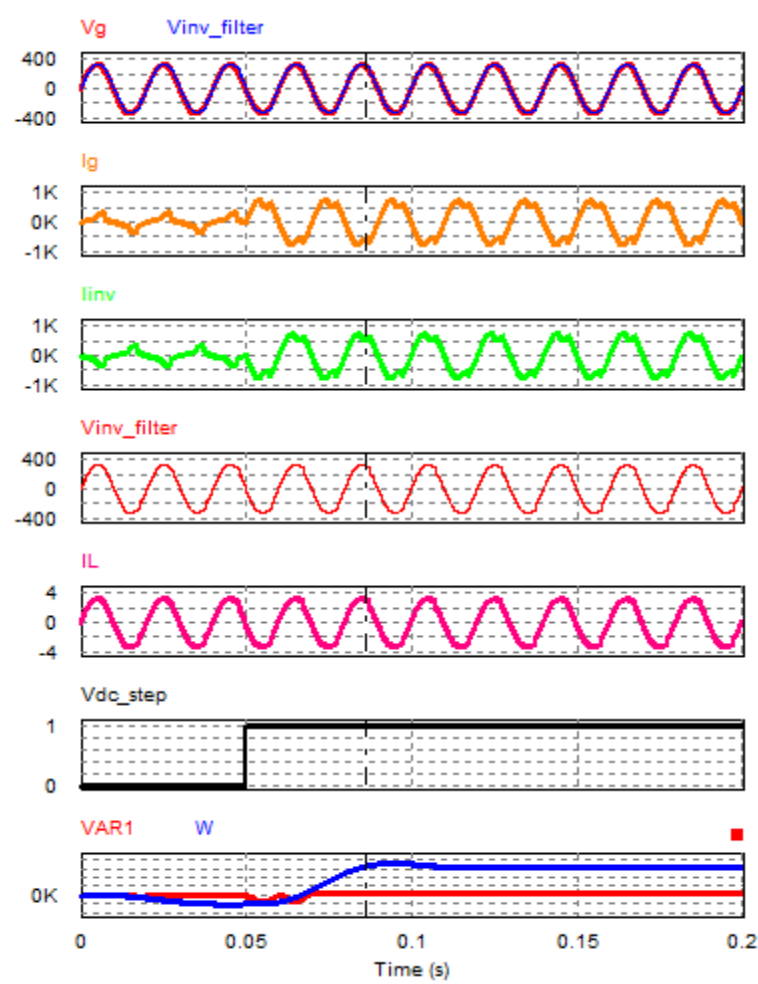

Figure 15. Grid-connected during voltage swell $(\mathrm{Vg}=400 \mathrm{~V})$

To support grid voltage during the sagging time, therefore the inverter should inject reactive power into the grid system. Another case, when the grid voltage on the swelling time, so the inverter should absorb the reactive power to reduce the voltage rise. 


\section{Conclusions}

This simulation provides a solution to design the singlephase grid-connected inverter becomes a smart system. inverter injects the active power during normal voltage mode, and also possible to absorb and inject the reactive power during voltage swell and sag, respectively. In normal mode, the inverter can play the role as a load or unit source that is injected into the grid. When the active power is injected, so a grid voltage and current inverter should be in phase. The 90-degree phase difference between grid voltage and current inverter will generate the maximum reactive power.

\section{ACKNOWLEDGEMENT}

We would like to thank Direktorat Riset dan Pengabdian Masyarakat (DRPM) from Kementerian Ristek Dikti for funding this research through the funding scheme programs of "Penelitian Dosen Pemula (PDP)".

\section{REFERENCES}

[1] A. Anzalchi and A. Sarwat, "Overview of technical specifications for grid-connected photovoltaic," Energy Convers. Manag., vol. 152, pp. 312-327, Nov. 2017.

[2] A. Cabrera-Tobar, E. Bullich-Massagué, M. AragüésPeñalba, and O. Gomis-Bellmunt, "Review of advanced grid requirements for the integration of large scale photovoltaic power plants in the transmission system," Renew. Sustain. Energy Rev., vol. 62, pp. 971-987, Sept. 2016.

[3] M. A. Eltawil and Z. Zhao, "Grid-connected photovoltaic power systems: Technical and potential problems-A review," Renew. Sustain. Energy Rev., vol. 14, no. 1, pp. 112-129, 2010.

[4] IEEE, "IEEE Recommended Practices and Requirements for Harmonic Control in Electric Power Systems," IEEE Standard 519-1992.

[5] Mao Xiaolin, Ayyanar Rajapandian, Krishnamurthy Harish $\mathrm{K}$, "Optimal variable switching frequency scheme for reducing switching loss in single-phase inverters based on time-domain ripple analysis." IEEE Trans Power Electr., vol.24, no.4, pp. 991-1001, April 2009.

[6] Venkatachalam KC, Jovitha J, Karpagam J, “ An experimental investigation on a multilevel inverter for solar energy applications," Int J Electr Power Energy Syst., vol.47, pp. 157-67, 2013

[7] X. Chen, H. Zhang, and J. Zhao, "A new Improvement Strategy based on hysteresis space vector control of Gridconnected inverter," APAP 2011 - Proc. 2011 Int. Conf. Adv. Power Syst. Autom. Prot., vol. 2, pp. 1613-1617, 2011.

[8] V. T. Tran and D. Sutanto, "Simple structure for reactive power control of AC photovoltaic modules," Australasian Universities Power Engineering Conference (AUPEC), Wollongong, pp. 1-6, 2015.

[9] L. B. G. Campanhol, S. A. Oliveira Da Silva, L. P. Sampaio, and A. O. Azauri, "A grid-connected photovoltaic power system with active power injection, reactive power compensation and harmonic filtering," Brazilian Power Electron. Conf. COBEP 2013 - Proc., Gramado, pp. 642-649, 2013.
[10] E. Pouresmaeil, B. J. Norregaard, M. Mehrasa, O. Erdinc, and J. P. S. Catalao, "A control algorithm for the stable operation of interfaced converters in microgrid systems," IEEE PES Innov. Smart Grid Technol. Conf. Eur., Istanbul, 12-15 Oct. 2014.

[11] L. Wang, Q. Jiang, L. Hong, C. Zhang, and Y. Wei, “A novel phase-locked loop based on frequency detector and initial phase angle detector," IEEE Trans. Power Electron., vol. 28, no. 10, pp. 4538-4549, 2013.

[12] N. Jaalam, N. A. Rahim, A. H. A. Bakar, C. K. Tan, and A. M. A. Haidar, "A comprehensive review of synchronization methods for grid-connected converters of renewable energy source," Renew. Sustain. Energy Rev., vol. 59, pp. 14711481, 2016.

[13] M. I. Munir, T. Aldhanhani, and K. H. Al Hosani, "Control of Grid Connected PV Array using P \& O MPPT Algorithm," Ninth Annual IEEE Green Technologies Conference (GreenTech), Denver, pp. 52-58, 2017.

[14] C. Chang, Y. Lin, Y. Chen, and Y. Chang, "Simplified Reactive Power Control for Single-Phase Grid-Connected Photovoltaic Inverters,” IEEE Trans. Ind. Electron., vol. 61, no. 5, pp. 2286-2296, 2014.

[15] A. Kusko and M. T. Thompson, Power Quality in Electrical Systems, Mc Graw Hill, 2007. 